\title{
Delayed partial reinforcement: Length of delay interval and the relationship of independence
}

\author{
STEVEN J. HAGGBLOOM \\ Arkansas State University, State University, Arkansas 72467 \\ and \\ E. J. CAPALDI \\ Purdue University, Lafayette, Indiana 47907
}

\begin{abstract}
In Experiment 1, groups received a 0-, 15-, 30-, or 60-sec delay of reinforcement on the rewarded trials of a partial reinforcement schedule (delayed PR). A 15-sec reinforcement delay did not reduce acquisition speeds compared with no delay. With delays of 30 and $60 \mathrm{sec}$, decremental effects of delayed PR were obtained for the first time, with a 60 -sec delay of reinforcement producing much slower running than the 0 - or 15-sec delays and the 30-sec delay group intermediate. In Experiment 2, two groups received a 60-sec delay of reinforcement, combined in one case with PR and in the other with consistent reinforcement (CR). The delayed PR group ran faster than the delayed CR group in acquisition in all alley sections. The results were discussed with reference to the role of inhibition in producing behavioral decrements under delayed reinforcement.
\end{abstract}

Generally speaking, delay of reinforcement has decremental effects on acquisition performance. The reinforcement level principle (Capaldi, in press-a) predicts, however, that the decrement will be less when delay is imposed on a schedule of partial reinforcement (PR) than when imposed on a consistent reinforcement (CR) schedule.

Numerous experiments have examined the effects of increasingly delayed CR. Under CR there is little question that performance is inversely related to the length of the delay interval (Campbell \& Knouse, 1972; Tarpy \& Sawabini, 1974). Much less is known about delayed PR; the effects of different delay intervals under PR having been investigated only recently (Capaldi, in press-b).

Capaldi (in press-b) reported that acquisition behavior under delayed PR was not only less sensitive to delay than acquisition under delayed $\mathrm{CR}$, as was expected by the reinforcement level view, but was independent of the length of the delay interval. The delay intervals used $(0$ vs. $10 \mathrm{sec}$ in Experiment $1 ; 0,10,15$, and $20 \mathrm{sec}$ in Experiment 2), although relatively short, produced marked response decrements under CR.

The relationship of independence under PR between performance and length of reinforcement delay (henceforth called simply the relationship of independence) obtained by Capaldi (in press-b) has important consequences for the partial reinforcement acquisition

This research was supported in part by National Institute of Child Health and Development Grant HD 04379 to E. J. Capaldi. Requests for reprints should be addressed to Steven J. Haggbloom, Department of Psychology, Arkansas State University, P. O. Box 2127, State University, Arkansas 72467. effect (PRAE). Faster running by PR than by CR groups during acquisition defines the PRAE. Because PR speeds remain constant with increasing delays, the relationship of independence, whereas CR speeds decrease with increasing delays, the PRAE increases as delay increases (Capaldi, in press-b).

The relationship of independence is not predicted by any existing theoretical explanation of delayed reinforcement effects (although it may be accommodated by the reinforcement level view, e.g., see Capaldi, in press-a). Because of its potential importance in understanding the effects of delayed reinforcement as well as PR phenomena, the relationship of independence warrants further study. The purpose of the first experiment reported here was to investigate the relationship of independence under PR acquisition at reinforcement delays beyond the range of $0-20 \mathrm{sec}$ previously employed.

\section{EXPERIMENT 1}

The four groups in Experiment 1 received identical schedules of PR but different delays of reinforcement on reinforced trials. The delay intervals used were 0 , 15, 30, and $60 \mathrm{sec}$. In previous experiments (Capaldi, in press-b), the relationship of independence held in acquisition with delays in the 0 - to 20 -sec range. Of principal concern was whether the relationship of independence would hold for delays as long as 30 and $60 \mathrm{sec}$.

\section{Method}

Subjects. The subjects were 40 male albino rats, 100 days 
old at the start of the study, purchased from the Holtzman Company, Madison, Wisconsin.

Apparatus. The apparatus was the same as that employed by Capaldi (in press-b). It consisted of a runway $208.4 \times 22.9 \times 10.2 \mathrm{~cm}$ wide. The runway was painted flat gray throughout and had a hardware cloth lid. The initial $20.3 \mathrm{~cm}$ of the runway served as a startbox and was separated from the rest of the runway by a manually operated guillotine door. The last $30.5 \mathrm{~cm}$ of the runway served as a goalbox and was also separated from the rest of the alley by a guillotine door. Raising the startbox docr activated the first of three clocks $(.01 \mathrm{sec})$; other clock functions were controlled by photoelectric circuitry. Start, run, and goal times were measured over respective distances of $5.1,132.1$, and $39.4 \mathrm{~cm}$ beyond the startbox door.

The goalbox contained a brass $5.1 \times 10.2 \times 3.8 \mathrm{~cm}$ food cup with a metal $3.8 \times 3.2 \times 1.9 \mathrm{~cm}$ inset which held the food pellets on reinforced trials. A solenoid-operated aluminum lid covered the food cup on all reinforced trials, preventing access to the pellets. The lid was recessed in the goal cup in such a manner that the rat could not, while remaining on all four feet, determine prior to breaking the last photobeam if it was in the open or closed position.

Pretraining. Subjects were housed in individual cages with food and water freely available. Deprivation, which consisted of $12 \mathrm{~g} /$ day of Wayne Lab Blox, began on Day 1 of pretraining. Water was always freely available. The rats were handled briefly on an individual basis on all pretraining days. On Days 12-14 each rat received $1545-\mathrm{mg}$ Noyes food pellets in the home cage. The number of pellets eaten either in the home cage or in the apparatus was always subtracted from the $12-\mathrm{g}$ daily ration. At the end of pretraining, the rats were randomly divided into four groups of 10 rats each.

Experimental training. Experimental training began on Day 15 of deprivation. The 4NR schedule used by Capaldi (in press-b) in Experiment 2 was used. Under the 4NR schedule there were five trials each day, the first four always being nonreinforced, the last always being reinforced. There were 20 days of such acquisition training. On nonreinforced trials the rats were confined to the goalbox for $20 \mathrm{sec}$. On reinforced trials the rats received $1545-\mathrm{mg}$ Noyes pellets and were removed from the goalbox as soon as the pellets were eaten. On nonreinforced trials the lid covering the food cup was withdrawn, clearly exposing the empty contents of the food cup. Thus, all groups received immediate nonreinforcement. On reinforced trials the lid of the food cup was in the closed position. The lid opened either immediately after the last photobeam was broken (Group PR-0) or after a delay of $15 \mathrm{sec}$ (Group PR-15), $30 \mathrm{sec}$ (Group PR-30), or $60 \mathrm{sec}$ (Group PR-60). This delay procedure, one cue occurring on nonreinforced trials (open food cup) and another on reinforced trials (closed food cup), was called the correlated procedure (see Capaldi, in press-b).

The rats were run in squads of four, one from each group per squad. The running order of the four rats in a squad was randomized daily, and all rats in a squad received trial $\mathrm{N}$ before any rat received trial $\mathrm{N}+1$. This produced an intertrial interval of 4-5 $\mathrm{min}$.

Subjects were allowed $60 \mathrm{sec}$ to complete any runway section. If more than $60 \mathrm{sec}$ was required, the time in excess of $60 \mathrm{sec}$ was added to the time required to complete the next alley section. If a rat did not enter the goalbox within $180 \mathrm{sec}$, it was placed in the goalbox.

\section{Results}

Figure 1 shows running speeds (centimeters/second) in blocks of 2 days for each of the four groups in the run, or middle, section of the runway. The run section data shown in Figure 1 are entirely representative of those obtained in the start and goal segments of the apparatus. All five trials of each day were included in all figures and analyses reported in this paper. As in Capaldi (in press-b), running speeds under the 4NR schedule were slow on the first (nonreinforced) trial of the day. Over the remaining trials, behavior became rapid and nondifferential. The differences between groups shown in Figure 1 were not uniquely associated with any particular trial, but rather occurred across the five daily trials.

The results obtained in Experiment 1 are clear; by the end of acquisition, Groups PR-0 and PR-15 did not differ, but those groups ran faster than Group PR-30, which in turn ran faster than Group PR-60. An analysis of variance applied to speeds on the last block of acquisition trials indicated that the groups differed significantly $[\mathrm{F}(3,36)=5.09, \mathrm{p}<.01]$. Subsequent Newman-Keuls tests indicated that only one difference failed to reach significance at the .05 level or better, that between Groups PR-0 and PR-15.

\section{Discussion}

The relationship of independence held during acquisition in Experiment 1 for groups given 0 - and 15-sec delayed PR, as it had in previous experiments (Capaldi, in press-b). In other words, Groups PR-0 and PR-15 performed alike in acquisition. The relationship of independence apparently breaks down somewhere beyond a 15-sec delay, inasmuch as Group PR-30 ran slower than Groups PR-0 and PR-15 and Group PR-60 ran slower than Group PR-30. Thus, delayed reinforcement had decremental effects on acquisition performance under PR, as it does under CR, but the decrement under PR was in evidence only at relatively long delays.

\section{EXPERIMENT 2}

As indicated earlier, the relationship of independence has consequences for PR phenomena, viz., the PRAE increases as delay increases (Capaldi, in press-b). The results of Experiment 1 indicate that behavior is quite severely depressed under delayed PR when the delay interval is $60 \mathrm{sec}$. Despite this, is PR acquisition at a 60-sec delay superior to CR acquisition, or at a $60-\mathrm{sec}$ delay do PR and CR groups fail to differ? The purpose of Experiment 2 was to determine whether the PRAE

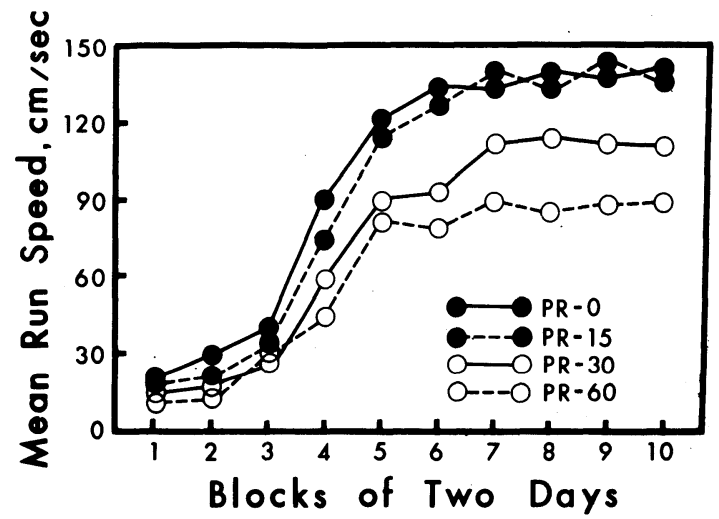

Figure 1. Mean speed in the run section for each of the four groups in Experiment 1 in blocks of 2 days. 
would occur despite the behavioral decrement produced by a 60 -sec delay of reinforcement.

\section{Method}

Subjects. Twenty rats of the same description as those in Experiment 1 were employed.

Apparatus. The apparatus was the same as that in Experiment 1.

Procedure. All aspects of the procedure employed in Experiment 2 were, except where specifically noted, identical to procedures in Experiment 1. Group PR-60 received partial reinforcement and a 60 -sec delay on the daily reinforced triai. Group CR-60 was reinforced on each of the five daily trials and received a $60-\mathrm{sec}$ delay of reinforcement on each trial. The rats were run in squads of four, two from each group per squad. This produced an intertrial interval of about $5 \mathrm{~min}$.

\section{Results}

Figure 2 shows running speeds (centimeter/second) in blocks of 2 days for Groups PR-60 and CR-60 in the start, run, and goal sections of the runway. Figure 2 shows that by the end of acquisition in all alley sections Group PR-60 ran faster than Group CR-60, a PRAE, with the difference being largest in the start section and about equal in the run and goal sections. Analysis of variance applied to speeds on the last trial block revealed that the difference between Group PR-60 and Group CR-60 was significant in all alley sections $[\operatorname{Fs}(1,18)=10.23,8.52$, and 7.75 , ps $<.05$ in start, run, and goal, respectively].

\section{Discussion}

Although a 60-sec delay of reinforcement has marked decremental effects on behavior when combined with a PR schedule (Experiment 1), the results of Experiment 2 indicate that the decrement is much less than that produced by a 60 -sec delay

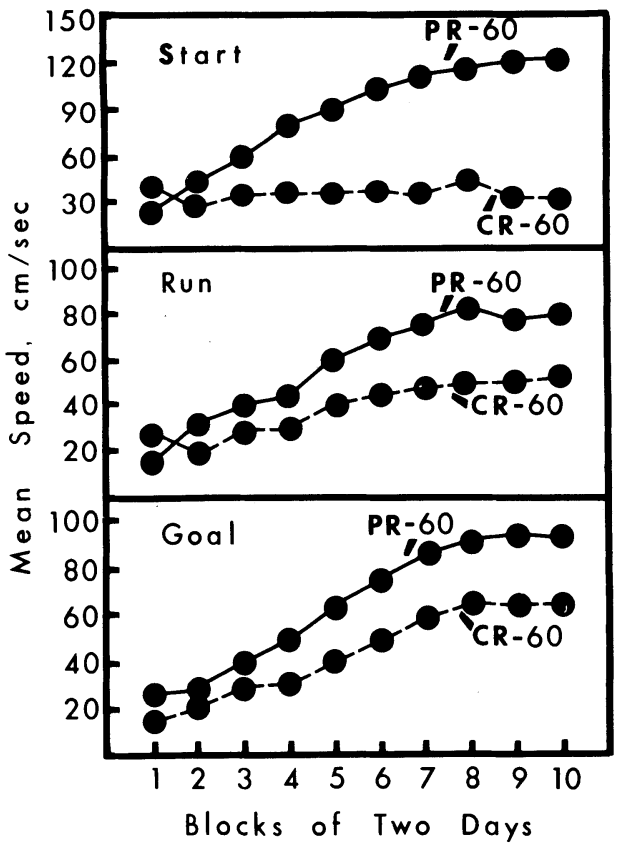

Figure 2. Mean speed in each alley section for both groups in Experiment 2 in blocks of 2 days. combined with a CR schedule. In Experiment 2 there was a large and reliable PRAE, with Group PR-60 running faster than Group CR-60. In experiments employing immediate reinforcement, the PRAE has been difficult to obtain and has been reported only for early (e.g., start) segments of the alley. Indeed, PR groups frequently run slower than CR groups in the goal section (see Robbins, 1971). The very substantial decrement in speeds under delayed CR is thereby emphasized by the fact that in Experiment 2 there was a substantial PRAE in goal, as well as in earlier, alley segments.

\section{GENERAL DISCUSSION}

The major results of the present experiments were as follows. First, decremental effects of delayed reinforcement were obtained for the first time in groups given delayed PR. In previous experiments (Capaldi, in press-b), the relationship of independence held for all delay intervals tested, a range of intervals from 0 to $20 \mathrm{sec}$. Here, the relationship of independence held in acquisition with a 15-sec delay, whereas increasingly decremental effects were obtained at 30 - and 60 -sec delays of reinforcement. Second, despite the decremental effects of a 60-sec delay of reinforcement under PR, there was a substantial PRAE in Experiment 2. The PRAE under delayed reinforcement appears to be a highly reliable phenomenon (see Capaldi, in press-b) and a direct consequence of the greater behavioral decrements produced by delayed CR.

Consider further the greater behavioral decrements produced by delayed $C R$ than by delayed PR. The reinforcement level view (Capaldi, in press-a, in press-b) emphasizes the role of inhibition in producing behavioral decrements under delayed reinforcement. A detailed explanation of this view has been presented elsewhere, so it will be only briefly described here (see Capaldi, in press-a). According to the reinforcement level principle, rats learn about the conditions of reinforcement (e.g., they acquire an expectancy for a given magnitude of reinforcement). Inhibition is acquired on trials when the reward obtained falls short of expectancy. Since a delayed reinforcement trial approximates a nonreinforced trial until the delay terminates, expectantancy would presumably exceed reinforcement during the delay interval and inhibition would be acquired on delay trials. Now, expectancy is assumed to be greater under CR than under PR, so inhibitory growth under CR would tend to exceed that under PR. Since PR and CR groups respond nearly alike with immediate reinforcement, the inhibition differential produced by delayed reinforcement would favor, as it did here, faster running in a group given delayed $P R$ than in a group given delayed CR.

Consider now the relationship of independence and the postponement to long delay intervals of the decremental effects of delay under PR. According to the reinforcement level view, the strength of conditioning that can be attained with a given reinforcer is not necessarily reduced by delay. Indeed, since expectancy under PR tends to be less than that under CR, the reinforcement level principle predicts that PR groups, whether given immediate or delayed reinforcement, would acquire effective habit strength (i.e., habit strength minus inhibition) in excess of that producing asymptotic running speeds. If delayed PR groups acquired "excess habit" (see Capaldi, 1974), small amounts of inhibition acquired with short delays might not reduce effective habit below the value needed to produce asymptotic running. Hence, short delay and immediate reinreinforcement groups would respond alike. Suppose, for examexample, that running speed becomes asymptotic when effective habit $=100$. If under immediate reinforcement $P R$ we assume that effective habit $=130$ and we let effective habit be reduced by the subtraction of, say, 15 units of inhibition with a $15-\mathrm{sec}$ delay, 40 units of inhibition with a 30-sec delay, and 75 units of inhibition with a 60-sec delay, the decremental effects of delay would appear, as in Experiment 1, only in the 30- and 60-sec 
delay groups, whereas the relationship of independence would hold for delays of less than $30 \mathrm{sec}$.

It should be emphasized that what has here been called the relationship of independence is a shorthand description of behavior on a PR schedule with zero or short delays of reinforcement. We are not proposing a threshold function for the growth of inhibition or habit. Rather, we are suggesting that inhibition increases continuously as delay increases but, because of excess habit acquired under PR, the decremental effects of delay on behavior do not occur at relatively short delay intervals.

\section{REFERENCES}

Campbell, P. E., \& Knouse, S. B. Extinction following delayed reward: A review. Psychonomic Monograph Supplements, 1972, 4(Whole No. 63).
Capaldi, E. J. Partial reward either following or preceding consistent reward: A case of reinforcement level. Journal of Experimental Psychology, 1974, 102, 954-962.

CaPaldi, E. J. Reinforcement level: An expectancy-associative approach to relative reinforcement and nonreinforcement effects. In G. McCain \& J. Bearwalt (Eds.), The Arlington symposium on learning. Stamford, Conn: Greylock, in press. (a)

CAPALDI, E. J. Effects of schedule and delay of reinforcement on acquisition speed. Animal Learning \& Behavior, in press. (b)

Robbins, D. Partial reinforcement: A selective review of the alleyway literature since 1960. Psychological Bulletin, 1971, 76, 415-431.

TARPY, R. M., \& SAWABINI, F. L. Reinforcement delay: A selective review of the last decade. Psychological Bulletin, 1974, 81, 984-997.

(Received for publication September 6, 1978.) 